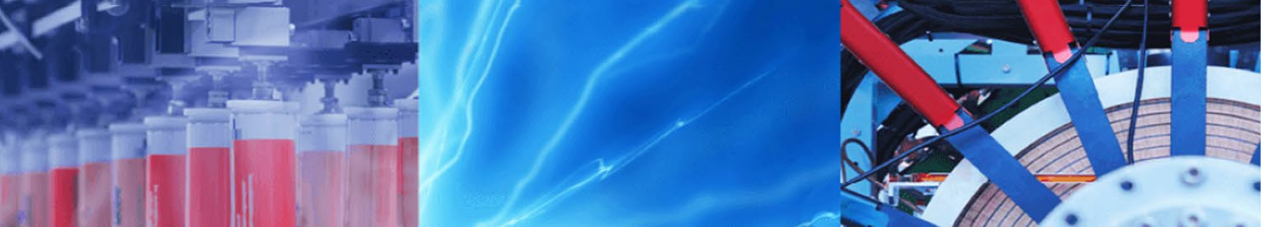

Research Article

\title{
Impact of machining-induced surface defects on the edge formability of commercially pure titanium sheet at room temperature
}

\author{
J. S. Kwame ${ }^{1}$ D $\cdot$ E. Yakushina ${ }^{2} \mathbb{D} \cdot$ P. Blackwell ${ }^{1,2} \mathbb{D}$
}

Received: 30 November 2019 / Accepted: 4 November 2020 / Published online: 16 November 2020

(c) The Author(s) 2020 OPEN

\begin{abstract}
Despite the good properties of titanium, which have drawn the interest of various industries over the years, one of the major drawbacks of this material is its poor machinability. This has largely been attributed to its low thermal conductivity and elastic modulus. The ability to attain the optimum sheet edge performance during forming is dependent on the quality of the edges produced. Also, the demanding nature of aerospace part design has provoked the interest of both industry and academia to continually explore avenues tailored at enhancing part performance. The sort of edge surface integrity produced for aerospace part fabrication thus becomes a vital consideration in the quest to ensuring prime performance of components. This work seeks to study the influence of different machining-induced surface defects on the sheet edge performance of CP-Ti (grade 2) at room temperature. Hole expansion test was used to assess the edge surface formability of CP-Ti with different machining-induced edge defects. The research found that machining-induced surface defects act as stress concentration sites during the hole expansion test and have a major impact on the material flow. Electro-discharge machined edges were observed to exhibit high edge formability compared to laser and abrasive water jet cut edges due to the impact of machining-induced microstructural changes.
\end{abstract}

Keywords Edge defects $\cdot$ Hole expansion test $\cdot$ Edge formability $\cdot$ Edge forming limit

$\begin{array}{ll}\text { List of symbols } \\ \text { HET } & \text { Hole expansion test } \\ \text { HER } & \text { Hole expansion ratio } \\ d_{f} & \text { Final hole diameter } \\ d_{0} & \text { Initial hole diameter } \\ L F R & \text { Limiting forming ratio } \\ d_{\max } & \text { Maximum inside the diameter of finished } \\ & \text { flange } \\ C O P_{n} & \text { Crack opening distance } \\ D_{1}, D_{2} & \text { Final hole diameter at random points } 1 \text { and } 2 \\ D_{\text {corrected }} & \text { Final hole diameter without crack opening } \\ \varepsilon_{1} & \text { Major strain } \\ \varepsilon_{2} & \text { Minor strain } \\ \text { Ra } & \text { Arithmetic average height surface roughness } \\ \text { AWJ } & \text { Abrasive water jet } \\ \text { EDM } & \text { Electric discharge machining }\end{array}$

$\mathrm{RD} \quad$ Sheet rolling direction

HCP Hexagonally close packed

EBSD Electron backscatter diffraction

\section{Introduction}

Owing to their good mechanical properties and relatively low density, titanium and its alloys have been widely utilised in the aerospace industry for a variety of applications both in the airframe and in the engines [1]. There are a number of variants of the commercially pure titanium (CP-Ti) alloy generally reflecting differing oxygen contents. They all feature a predominantly alpha-grained hexagonally close packed (HCP) microstructure, which contributes to a reduced formability at room temperature due to the availability of limited

J. S. Kwame, james.kwame@strath.ac.uk| 'Department of Design, Manufacturing and Engineering Management, University of Strathclyde, Glasgow, UK. ${ }^{2}$ Advanced Forming Research Centre (AFRC), University of Strathclyde, Glasgow, UK. 
slip systems. CP-Ti exhibits mechanical anisotropy by virtue of its tendency to develop a strong crystallographic texture during plastic deformation [2,3]. Another factor restricting the use of titanium alloys is their sensitivity to surface inhomogeneity $[4,5]$. These surface inhomogeneities are sometimes instituted either during cutting operations, storage, transportation or during handling. Generally, titanium and its alloys are difficult to machine due to their low thermal conductivity as well as low elastic modulus [6]. Titanium's low thermal conductivity plays a major role in machinability in terms of its impact on the heat removal rate [7]. Commercially pure titanium exhibits a relatively more stable thermal conductivity with rising temperature when juxtaposed with its alloyed counterparts [7]. The cutting forces required to cut titanium are slightly higher than those for steels, and this combined with the nature of titanium's metallurgical features makes it comparatively more difficult to machine [8]. The vulnerability of titanium to surface deterioration during machining has a significant impact on the nature of the attained surface finish. Various research works conducted on the possibility of machining titanium with conventional $[9,10]$ and unconventional cutting methods $[11,12]$ have shown the responsiveness of the attained edge surface integrities to machining parameters. However, work directed at examining the impact of different machining parameters on the edge forming performance of sheet materials has not been previously examined. This research is directed at evaluating the influence of different machining methods and cut edge qualities produced with varying machining parameters on the edge formability of CP-Ti (grade 2).

An important consequence of the nature of sheet edge integrity is its influence on the part edge formability. Understanding the influence of sheet edge characteristics for aerospace structure fabrication provides vital information about the appropriateness of different cutting techniques for subsequent sheet forming operations. The hole expansion test (HET) is the standardised test adopted for characterising sheet metal edge stretchability. The HET is described by the hole expansion ratio (HER), which is computed from the initial and final hole diameters. HER values quantify the edge formability of sheet metals [13];

$\mathrm{HER}=\frac{d_{f}-d_{0}}{d_{0}} \times 100 \%$

where $d_{f}$-final diameter, $d_{o}$-initial diameter.

Another indicator used to define the hole edge flangeability of materials is the limiting forming ratio (LFR), which can be expressed as follows [14]:

$\mathrm{LFR}=\frac{d_{\max }}{d_{0}}$ where $d_{\max }$-maximum inside the diameter of finished flange, $d_{0}$-original hole diameter.

In order to ensure reduced variation in the attained HER values, the test must be terminated at the onset of edge fracture. However, complete reliance on visual inspection to terminate the test has been known to be a major source of data scatter in recorded HER values [15]. Various ways to reduce the variations in HER values have also been devised in some works. Larour et al. [16] in their work suggested an equation which could be used to correct the crack widths that emerge during HET:

$D_{\text {corrected }}=\frac{\left(\frac{D_{1}+D_{2}}{2}\right) \pi-\sum_{1}^{n} C_{n}}{\pi}$

By putting (3) into (1)

$\mathrm{HER}=\frac{D_{\text {corrected }}-D_{0}}{D_{0}}$

where $\mathrm{COP}_{\mathrm{n}}$ - crack opening distance; $\mathrm{D}_{\text {corrected }}$-final hole diameter without crack opening; $D_{0}$ - original hole diameter, $D_{1}, D_{2}$ - final hole diameter at random points 1 and 2 .

This work introduces the GOM ATOS optical non-contact measurement as a supplementary method for characterising the edge workability of materials.

\section{Experimental procedure}

\subsection{The material}

The researched material in this work is CP-Ti (grade 2) sheet with a thickness of $1.6 \mathrm{~mm}$. CP-Ti (grade 2) possesses a good strength to weight ratio and also has the ability to maintain its strength appreciably during deformation. The material also has good corrosion resistance and is largely employed in airframe skin applications.

\subsection{Material characterisation}

The material was mounted using a Buehler Simplimet 3000 mounting press. Grinding and polishing were performed using a Buehler Automet 300 Pro grinder-polisher machine. The samples were then electropolished using a Struers LectroPol-5 automatic electrolytic polishing and etching machine. A solution of $600 \mathrm{ml}$ methanol $+360 \mathrm{ml}$ butoxy-ethanol $+60 \mathrm{ml}$ perchloric acid was used as an electrolyte at $12^{\circ} \mathrm{C}$. Electron backscatter diffraction (EBSD) was performed to observe the microstructure, using a Quanta FEG 250 microscope. The micrograph of the supplied sheet showed fine equiaxed grains with a mean grain 
Fig. 1 Microstructure of supplied sheet; EBSD image

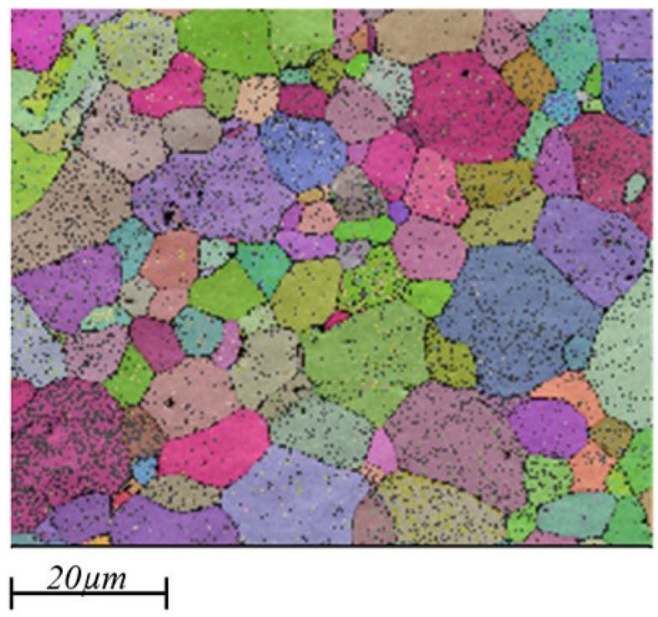

IPF colouring

Ti-Hex

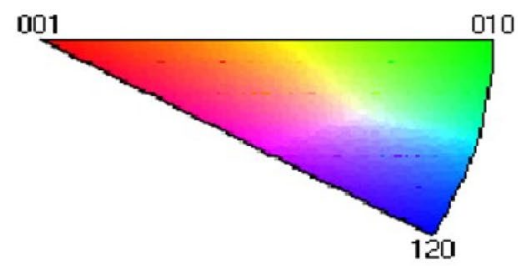

20

Table 1 Chemical elements

\begin{tabular}{lllllll}
\hline Constituent elements & $\mathrm{Ti}$ & $\mathrm{N}$ & $\mathrm{C}$ & $\mathrm{H}$ & $\mathrm{Fe}$ & $\mathrm{O}$ \\
\hline Composition, wt\% & Balance & 0.03 & 0.08 & 0.015 & 0.20 & 0.18 \\
\hline
\end{tabular}

Table 2 Mechanical properties at room temperature

\begin{tabular}{llll}
\hline Sheet direction & $\begin{array}{l}\text { Yield strength, } \\
\mathrm{MPa}\end{array}$ & $\begin{array}{l}\text { Tensile strength, } \\
\mathrm{MPa}\end{array}$ & $\mathrm{R}$ value \\
\hline $0^{0} \mathrm{RD}$ & 197.99 & 550.31 & 1.131 \\
$45^{0} \mathrm{RD}$ & 218.19 & 489.43 & 2.855 \\
$90^{0} \mathrm{RD}$ & 250.05 & 513.25 & 3.200 \\
\hline
\end{tabular}

size of $5.7 \pm 0.5 \mu \mathrm{m}$, as shown in Fig. 1. The chemical composition of the material is shown in Table 1.

\subsection{Mechanical properties}

Standard room-temperature uniaxial tensile tests consistent with ISO 6892-1:2016 were conducted on the samples using a Zwick/Roell Z150 tensile testing machine. The materials were plastically deformed at a constant strain rate of $0.001 \mathrm{~s}^{-1}$. An extensometer was also employed to capture the displacement of the sample during the tensile deformation process. The mechanical properties studied in three sheet directions are listed in Table 2. As is typical for rolled alloys of this type, the material exhibited highly anisotropic behaviour at room temperature, as shown in Fig. 2. Such anisotropic tendencies observed in CP-Ti (grade 2) are attributable to the material texture $[2,17]$ and its effects on slip and twinning activity [18].

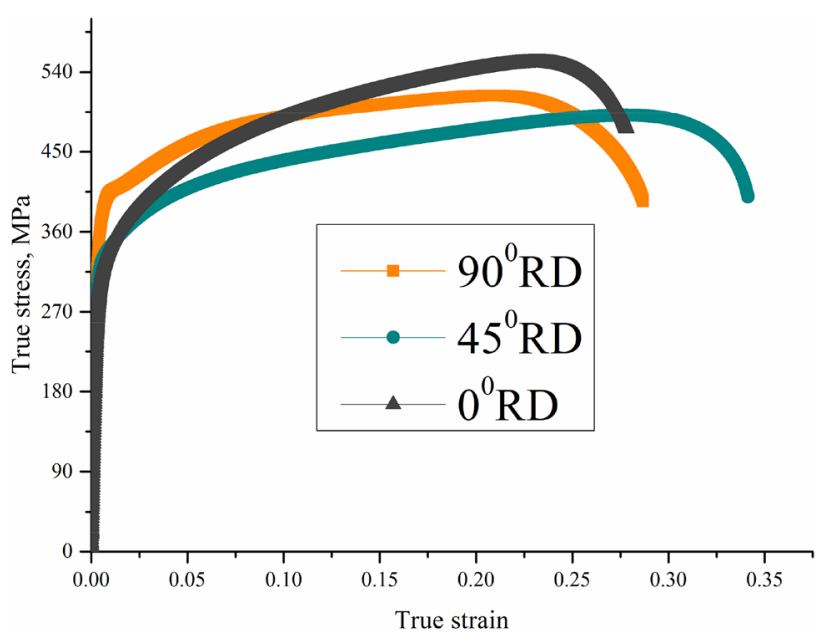

Fig. 2 True stress-strain curve

\subsection{Hole expansion test}

A Zwick/Roell BUP 1000 testing machine furnished with a testXpert II software was utilised to perform a HET on the test specimens. A punch speed of $1 \mathrm{~mm} / \mathrm{s}$ was used in this work, consistent with BS ISO 16630:2017. A blankholder force of $100 \mathrm{kN}$ was used to avoid the sheet from drawing-in during the testing process. The test was terminated when a crack through the entire edge thickness occurred. A GOM ARAMIS system with a $2448 \times 2050$ camera acquisition mode was used to capture the speckle pattern displacement during deformation. The GOM ARAMIS $5 \mathrm{M}$ (GigE) sensor type was used in this work with a measuring volume of $110 \times 95 \times 70 \mathrm{~mm}^{3}$. 


\subsection{Tool geometry}

The CP-Ti (grade 2) sheets were deformed with two different tool geometries; a 100-mm-diameter Nakajima/ hemispherical punch and a 30-mm-diameter conical punch with $60^{\circ}$ cone head, as shown in Fig. 3. The Nakajima punch exerts both horizontal and vertical loads on the hole edge via in-plane stretching, as shown in Fig. 3a. The conical punch on the other hand exerts vertical load on the hole edge via out-of-plane loading, as shown in Fig. 3b. The conical punch together with its die tool set was fabricated with dimensions consistent with BS ISO 16630:2017.

\subsection{Approach for material edge preparation}

Machining techniques known to be extensively adopted in industry for fabricating titanium sheets were analysed in this work. As such, the sort of edge surface finishes which are obtained under commercially viable machining conditions are examined in this research. The test samples were prepared by companies with specialisation in the respective machining technologies used. Thus, the edges surfaces examined for each machining method are surface quality ranges, which are commercially and industrially applicable for fabricating CP-Ti (grade 2). The nature of the edge microstructure produced from the industry standard machining qualities was examined to ascertain their influence on the edge forming performance of CP-Ti (grade 2) for an onward adoption in hole flanging operations.

The EDM samples were machined using a GF F1 440 CCS machine equipped with a $0.25-\mathrm{mm}$ brass wire with varying cutting parameters (pulse on duration time: 0.7 , 0.1 and $0.05 \mu \mathrm{s}$ for unfinished, semi-finished and finished edges). Test conditions for electro-discharge machining
(EDM) with respect to machining accuracy are governed by BS ISO 14137:2015. An AMADA LCG-3015AJ laser cutting machine furnished with a $4 \mathrm{KW}$ fibre laser and 2-mm beam diameter was used to machine the laser cut test samples. For the waterjet cutting, a Calypso waterjet machine with a 70-HP KMT pump charged with an abrasive feed of $400 \mathrm{~g} \mathrm{~min}^{-1}$ was employed with varying machining parameters (transverse cutting speeds: 250,400 , and $600 \mathrm{~mm} \mathrm{~min}^{-1}$ for finished, semi-finished, and unfinished edges, respectively) to achieve different surface finishes.

\section{Results and discussion}

\subsection{Machining-induced edge surface defects}

Figure 4 shows Alicona 3D micrographs of the three cut edge finishes realised after AWJ cutting. The unfinished surface is marked by the path traversed by the abrasive particles during the cutting process, resulting in deep surface grooves.

Figure 5 shows the various levels of edge surface finishes attained after EDM cutting. The observed surface morphology is typically marked with its thermal erosion characteristics. The severity of the post-machining surface features is a function of the extent of material melt re-solidification as well as the quantity of molten material carried away by the dielectric fluid during the cutting process. A 3D analysis of the edge surface micrograph revealed zones of high ridges, shallow craters, voids, and terrain features, as shown in Fig. $5 \mathrm{~d}$.

The laser cut edge surface was characterised by tracks of sporadic kerf width and striation formations with an attained edge surface finish of Ra $4.5 \mu \mathrm{m}$ (see Fig. 9c). (a)

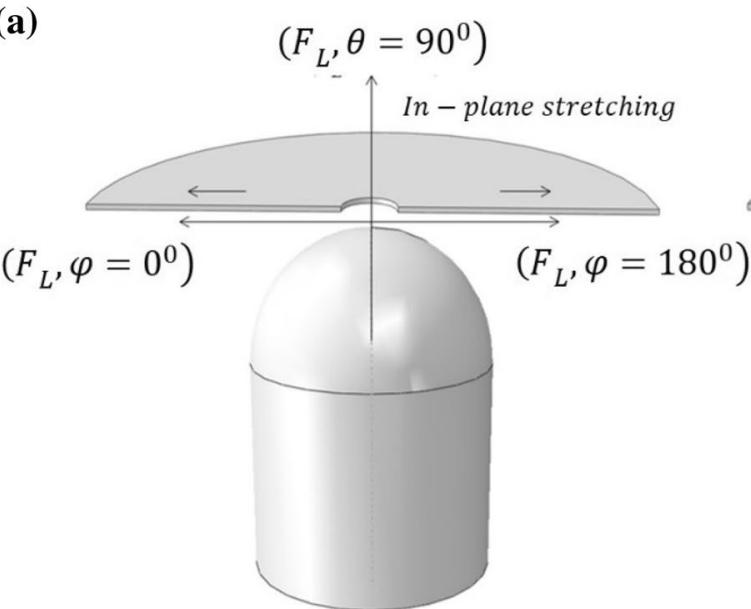

(b)

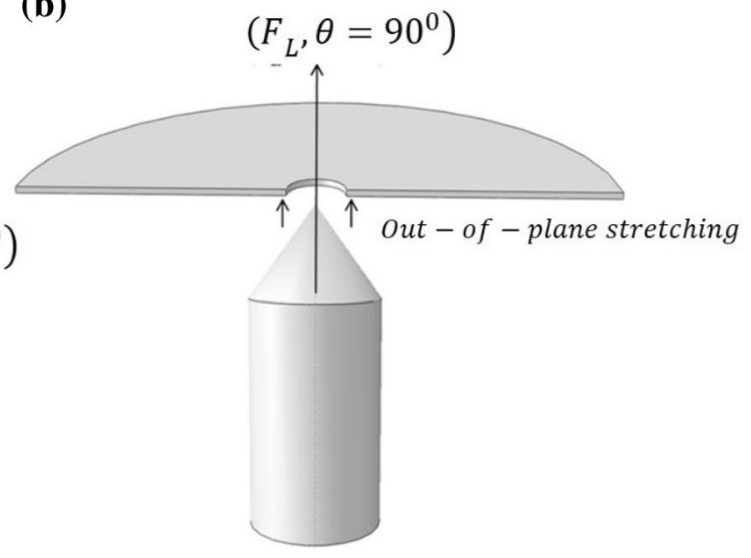

Fig. 3 Tool geometry and sheet loading condition: a hemispherical punch, $\mathbf{b}$ conical punch 
Fig. 4 Alicona 3D micrograph of edge surface finishes after AWJ cutting: a finished edge surface, $(\operatorname{Ra} \sim 3.8 \mu \mathrm{m}), \mathbf{b}$ semi-finished edge surface, (Ra $~ 5.4 \mu \mathrm{m}$ ), c unfinished edge surface ( $\operatorname{Ra} \sim 7.7 \mu \mathrm{m})$, with grooves from abrasive particle path
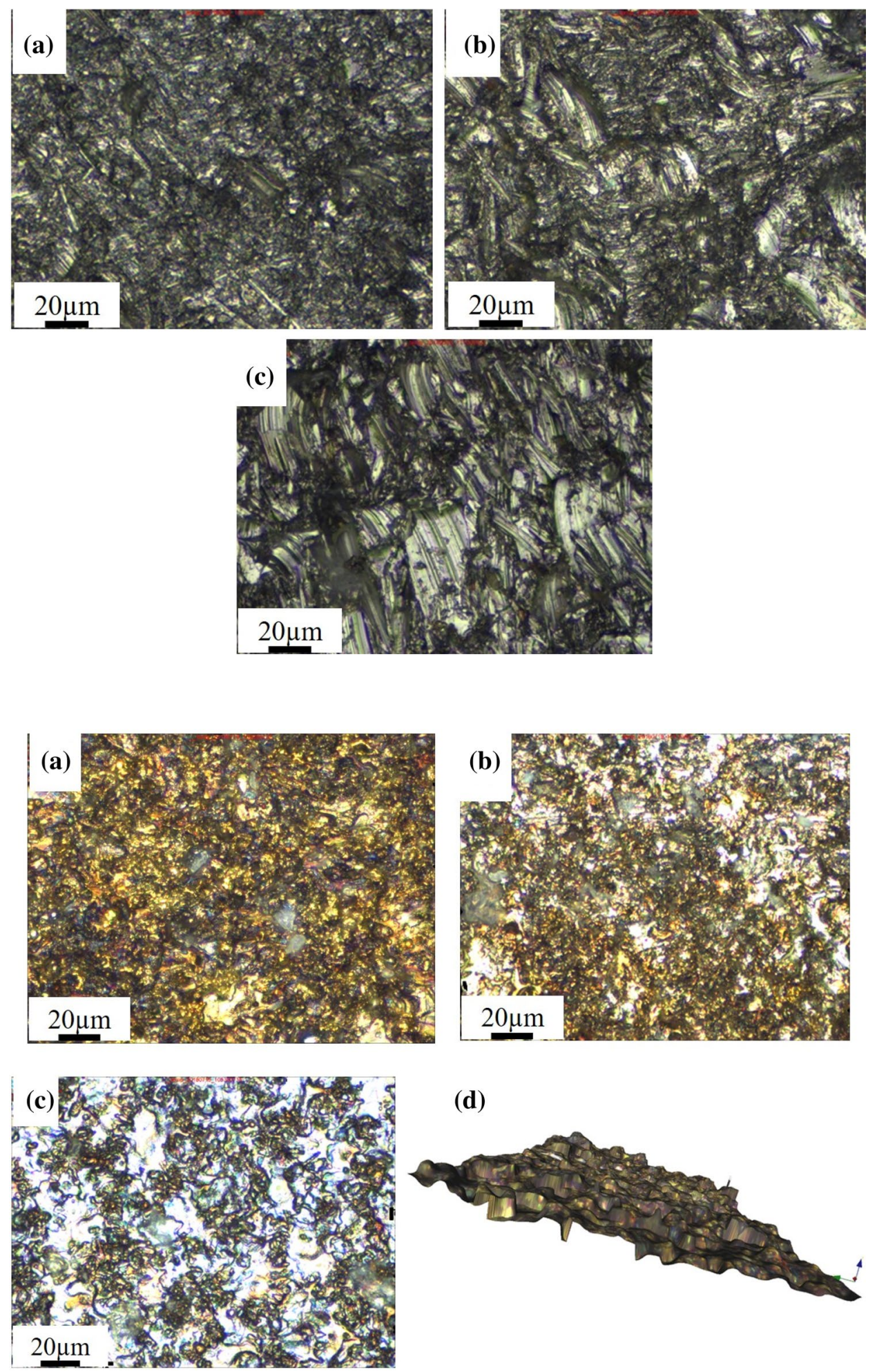

(d)

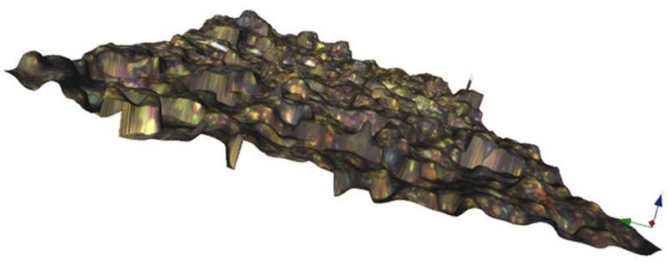

\subsection{Effect of different surface finishes on the HER: hemispherical punch}

Hole expansion tests with the hemispherical punch were performed on the material with the three different edge surface finishes after AWJ and EDM cutting. Three repeats were performed for each cutting regime to ensure the reproducibility of the results. Figure 6 shows the plot of the HER evaluated for all edge surface finishes studied.

The material showed a significant sensitivity to the quality of the edge surface finish with the HER values increasing as the edge surface roughness decreased for 


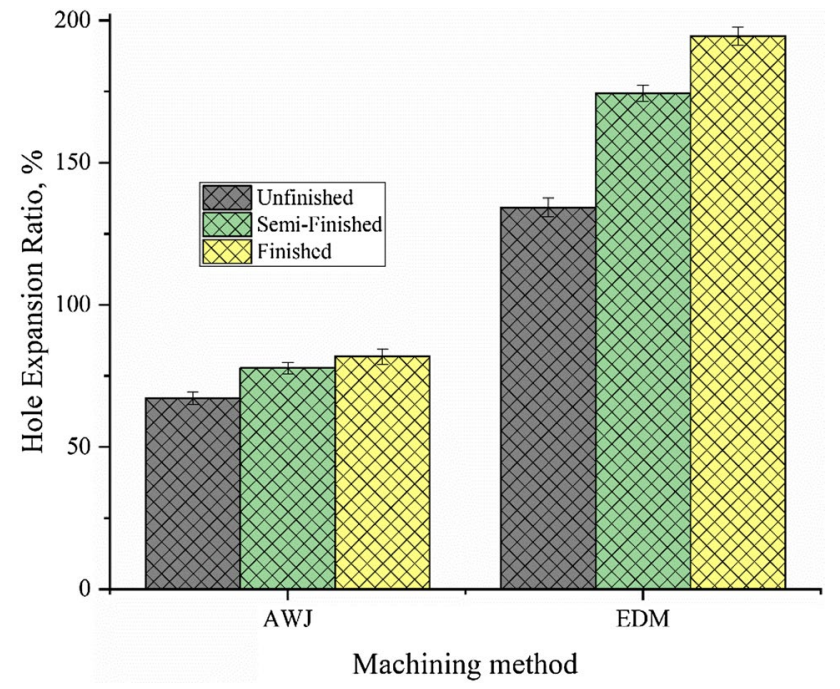

Fig. 6 HER for various edge surface finishes with hemispherical punch

both cutting methods. This trend could be attributed to the impact of the severity of the defects observed which varied with the quality of the surface finish. The more pronounced edge surface defects in terms of depth and size hindered the material flow more significantly compared to the subtler defect sizes seen in the more finely finished surfaces. The poorer the finish on the edge surface, the more severe its effect on the material formability. The quality of edge surface finishes in terms of machining-induced edge surface roughness and their accompanying defects thus plays a major role in the edge formability of CP-Ti (grade 2) at room temperature.

\subsection{Major and minor strain evolution: HET}

A digital image correlation-based optical non-contact technique was employed to measure the full-field strain values during the deformation process. A speckle pattern consisting of white paint sprayed with black dots was utilised. The speckle pattern application plays a significant role as the main conveyor of deformation information for the onward digital image correlation computation with GOM ARAMIS software. The GOM ARAMIS software tracks corresponding points of an image taken from a specklepatterned surface to compute the local strain values. The major and minor strain evolution across the sheet surface from the hole edge measured during the HET trials with the hemispherical punch movement during HET was analysed using GOM ARAMIS for all finished cut edge conditions, as shown in Fig. 7. The material showed a fracture strain value as high as $\sim 0.83-0.93$ for the EDM cut samples. The laser cut samples exhibited the lowest fracture strain of the three techniques ( 0.28-0.34) with AWJ showing an intermediate value between the other two ( 0.53-0.69), when tested under the same conditions. The reduced fracture strain values observed under laser cutting is thought to be due mainly to the machining-induced microstructure changes produced on the edge surface during the machining process hindering the edge formability considerably. Deformation strains concentrated around the hole edge area with reduced strains emerging away from the fabricated hole. An analysis of the major and minor strains around the hole edge using GOM ARAMIS was also done for all finished edge conditions. The results showed that the strain path is reminiscent of pure uniaxial tension
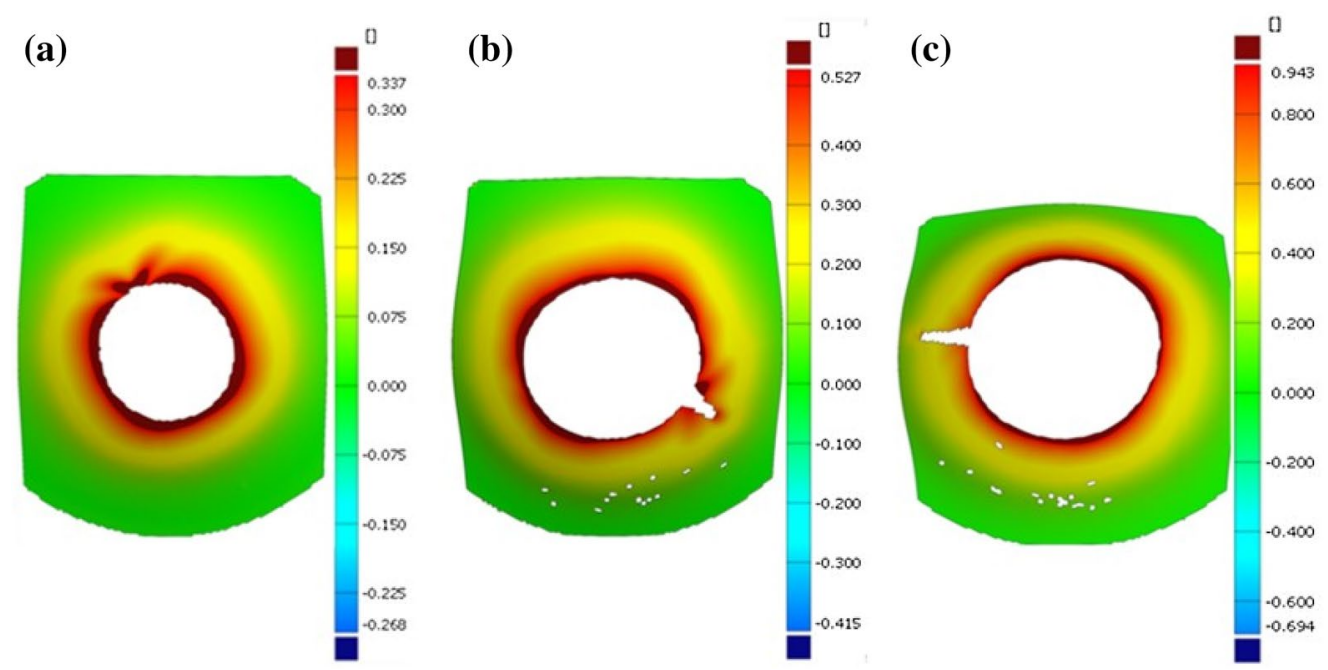

Fig. 7 Major and minor strain evolution during HET with hemispherical punch contour map for deformed: a laser cut edge surface, b AWJ cut edge surface, c EDM cut edge surface 
Fig. 8 Edge fracture limit
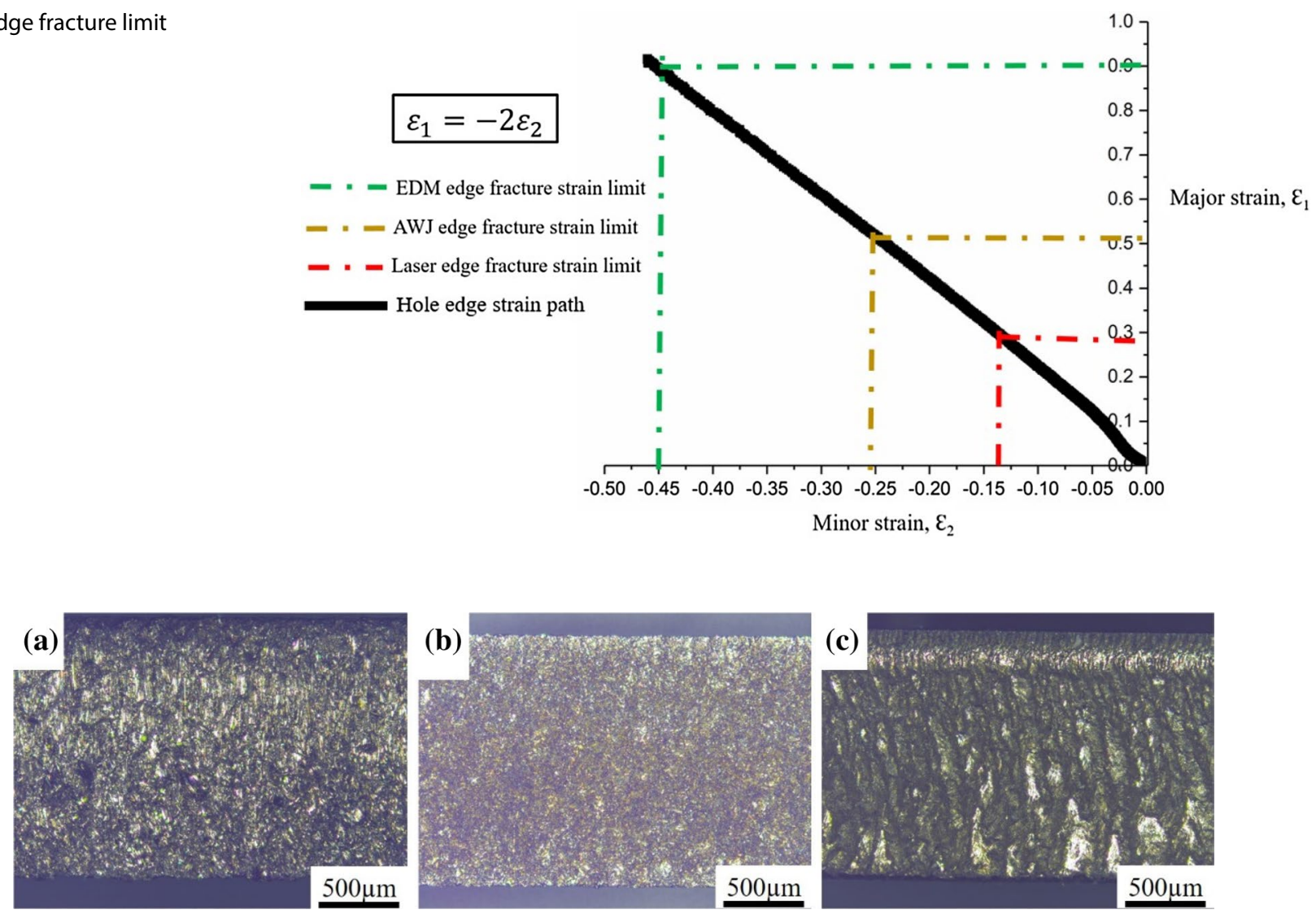

Fig. 9 Optical micrograph after different cutting methods: a AWJ, b EDM, c laser cut surface

$\left(\varepsilon_{1}=-2 \varepsilon_{2}\right)$ on the conventional forming limit diagram, as shown in Fig. 8.

This implies that during the HET, the stress state around the hole edge is pure uniaxial tension. This represents the deformation path traversed during the edge stretching process. The fracture strains evaluated with GOM ARAMIS during the HET can therefore be used to predict the edge formability limit of CP-Ti (grade 2) machined with the various cutting methods under study. Thus, the exact strains where the edge cracks begin to emerge could be predicted for each cutting method. The edge fracture limit strain values indicated on the graph are averages obtained for several repeated test results recorded for results shown in Fig. 10 for a hemispherical punch. The laser cut edge of CP-Ti (grade 2) shows a lesser edge forming limit compared to those observed in shear cut hot-rolled steels ( 0.43) [19].

\subsection{Effect of tool geometry on HER}

Low magnification images of the edge surfaces prepared with EDM, AWJ, and laser machining are shown in Fig. 9. As noted earlier, there were significant differences in the surfaces produced with the laser cut surface giving the

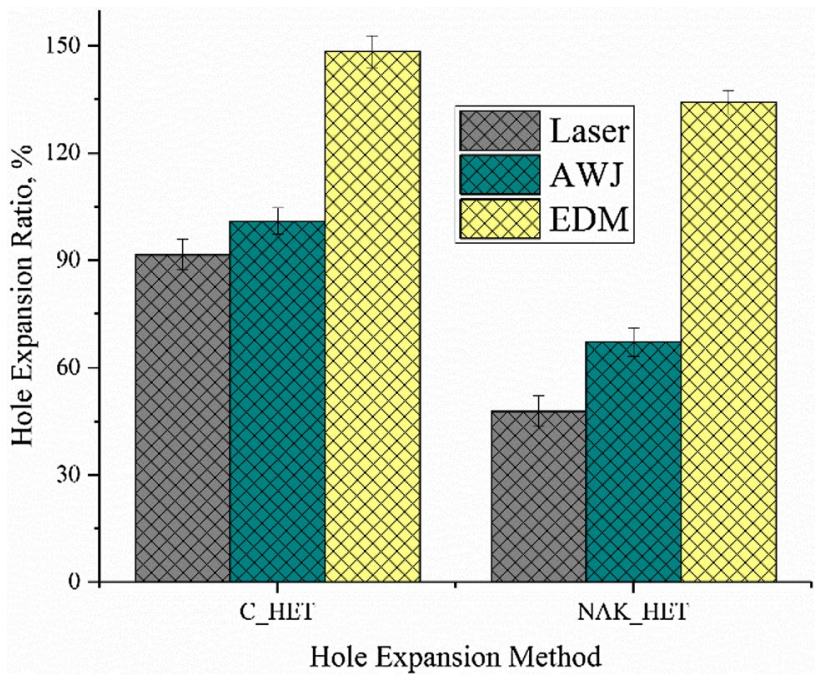

Fig. 10 Effect of tool geometry on HER

highest roughness and EDM the finest. Comparison of HER values determined with the hemispherical punch (NAK_HET) and standard conical punch (C_HET) is shown in Fig. 10. The conical punch showed higher edge formability tendencies for the machined edges as compared with 
the hemispherical punch. These differences are mainly due to the variation in loading orientation instigated by the various punch geometries. These differences also occur as a result of varying strain gradients induced at the test piece edge during the experimental trial.

The conical punch produces the highest stretching at the workpiece edge due to the non-uniformity in the strains produced at various parts of the edge surface. Thus, when using the conical punch, strain localisation is delayed since the edge is loaded out of plane and hence the trend. The hemispherical punch on the other hand loads the sheet in plane with a concomitant higher tendency for a more uniform strain gradient at the hole edge with an accompanying potential for earlier strain localisation. Pathak et al. [20] in their work on the edge formability of dual and complex phase steels also recorded higher HER values for conical punch compared to flat punches. Their work showed that the flat punch initiates cracks away from the hole edge since it loads the sheet under plain strain loading compared to the conical punch that exerts uniaxial tension at the hole edge.

For both tool geometries, however, failure is commenced under uniaxial tension near the hole edge. The similarities in the generated stress state near the hole edge and the occurrence of fracture at the hole edge make both tool geometries suitable for edge formability determination of the material. Both the hemispherical and conical punches also exhibited the same trend of edge formability behaviour in CP-Ti (grade 2) sheet after laser, AWJ and EDM cutting. This trend confirms the applicability of both tools for use in the assessment of the hole edge formability of the material. The tool geometry influence on the HER is telling mainly in terms of the loading conditions leading to varying HERs. The tool geometry performance is therefore responsive to the nature of the edge structure produced after the edge fabrication method, hence the varying results for different machining methods. Thus, the ultimate edge formability performance lies in the integrity of the attained edges/defects produced during the material fabrication process - the results reflecting the edge roughness trend illustrated in Fig. 9 and discussed at more length in Sect. 3.1. The tool geometry plays a massive role in terms of the optimum ways of loading the material with respect to the sheet material plane.

\subsection{Assessment of edge formability using GOM ATOS measurement}

The conical punch was used to flange the holes fabricated with either laser, AWJ or EDM cutting method. The thinning evolution around the flanged edge zone and the potential of each cutting technique during the test trial was assessed using GOM ATOS optical non-contact measurement method. Table 3 shows the results of the experimental trial for the various edge surface finishes. The test samples failed for laser as well as those for unfinished $(\mathrm{Ra} \sim 7.7 \mu \mathrm{m})$ and finished $(\mathrm{Ra} \sim 3.8 \mu \mathrm{m})$ AWJ surface qualities after the experimental trial. However, there was an improvement in the attained HER with the enhanced surface finish for both laser and AWJ fabricated edges. The linear relationship between the HER and surface finish quality was also matched with a corresponding reduction in edge thickness. The thinning evolution around the hole edge is a function of the type and quality of the cut edge finish. A smoother edge surface inhibits early fracture nucleation, which is reflected as a significant edge thinning before failure. The material exhibited higher thinning tendencies with the finished edges compared to their unfinished edge counterparts. The finished edge after EDM ( $R a \sim 0.8 \mu \mathrm{m})$ cutting also showed a higher HER compared to the unfinished EDM edge (Ra $3.7 \mu \mathrm{m})$ with a corresponding reduction in edge thickness.

With the improved edge finish after EDM cutting, however, the hole edge was successfully flanged with the 30-mm-diameter conical punch. The EDM cut edge recorded the lowest thickness zones around the flanged region $(\sim 0.9 \mathrm{~mm})$ followed by AWJ cut edge $(\sim 1.18 \mathrm{~mm})$ and laser-machined edge $(\sim 1.4 \mathrm{~mm})$, as shown in Fig. 11 . The nature of the edge microstructure after machining is therefore a major factor in the thinning evolution tendency at the hole edge of the material. Since the stress during the deformation process concentrates around the hole edge, the machining-induced surface features become a critical feature during HET in their role as stress raisers. The higher the thinning tendencies around the hole edge, the higher the ability of the material to flow and the higher the edge stretchability. GOM ATOS metrology characterisation of the hole edge thinning evolution observed in the studied fabrication methods is consistent with HER trends. Compared with GOM ARAMIS which focuses on the strain evolution during the HET, the GOM ATOS technique is directed at ascertaining the thickness evolution, which is indicative of material flow and could therefore provide a viable route for assessing the edge flangeability of materials.

\subsection{Hole edge fracture initiation}

Figure 12 shows SEM images of laser cut edges before and after HET. The surface of the undeformed edge after laser cutting was characterised by surface defects in the form of periodic striation formations produced by virtue of material remelt on the part surface followed by a rapid cooling, as shown in Fig. 12a. During HET, the uneven nature of the striations acts as stress concentration site due to the presence of zones with deep striation features. Thus, the onset 
Table 3 Thinning evolution with HER and edge surface finish after HET with conical punch

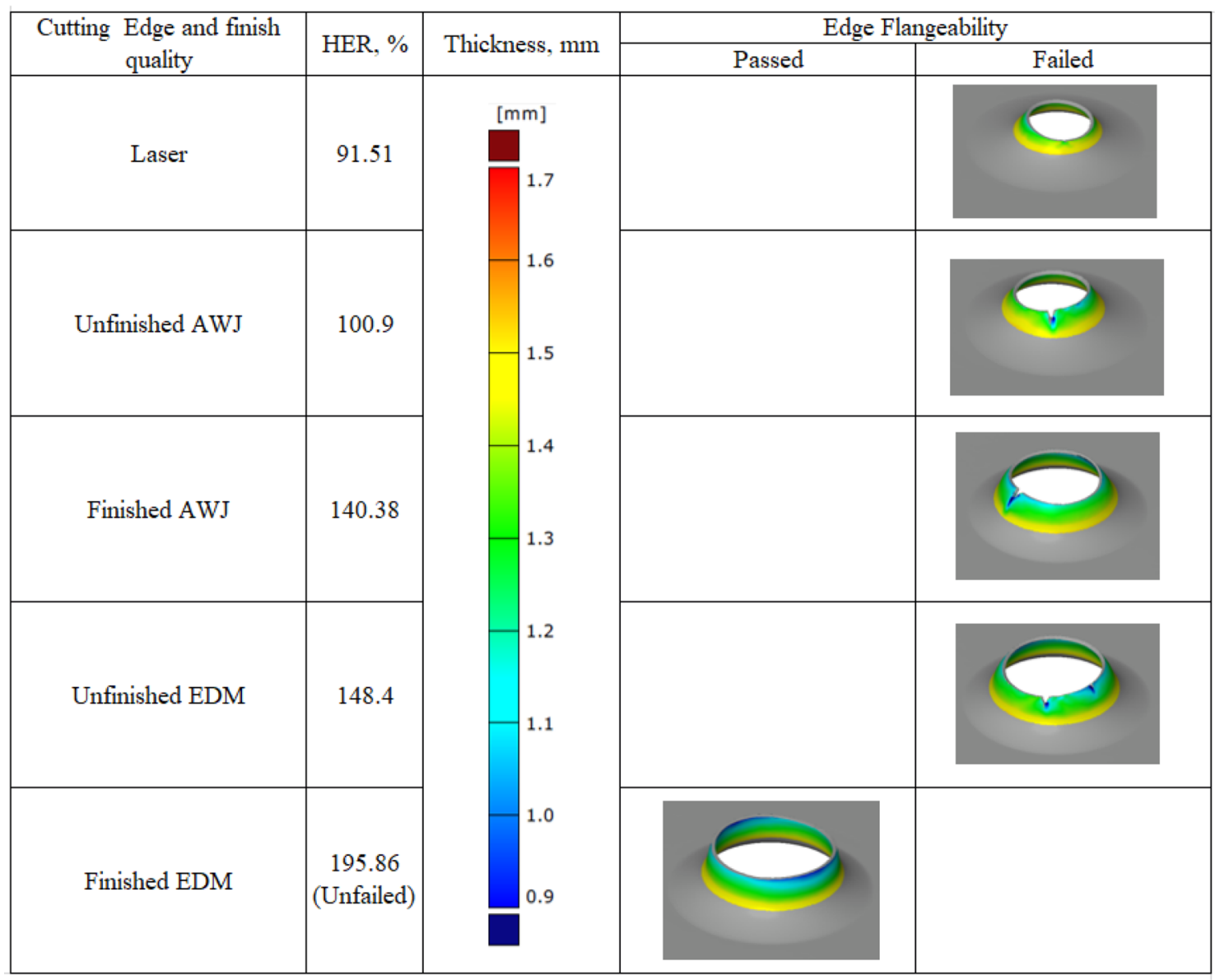

Fig. 11 Thinning evolution analysis after HET with conical punch: a finished EDM edge, $\mathbf{b}$ finished AWJ cut edge, c laser cut edge

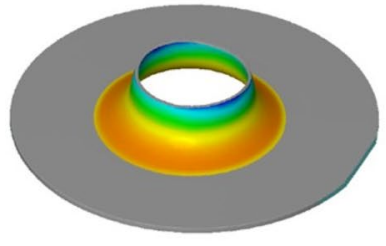

(a)

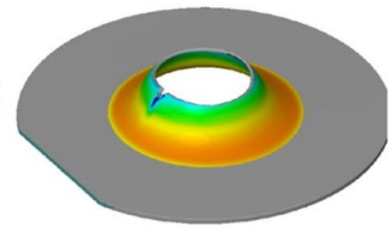

(b)

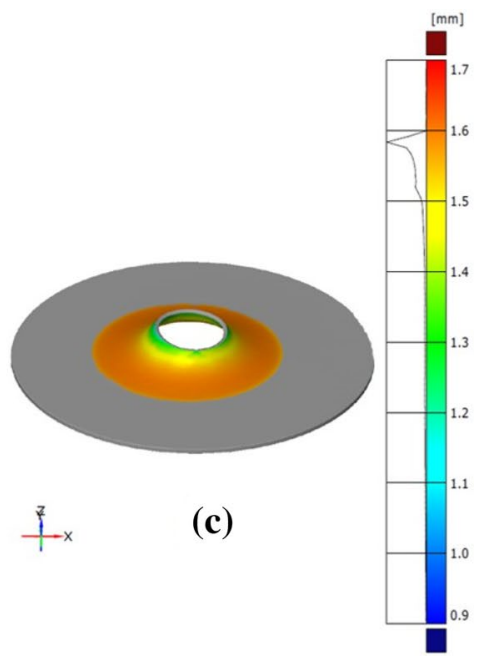

of crack initiation is observed at the trough of the striation formations, as shown in Fig. 12b. Analysis of a higher magnification micrograph of the laser crack surface after HET revealed the brittle inter-granular nature of the cracks (yellow dash lines) and the surface cracks rapidly propagated across the laser cut edge due to the brittle nature of the recast layer, as shown in Fig. 12c. Even though the cracks were initiated at the surface defect sites, the direction of crack propagation was influenced by the laser machininginduced microstructural changes. High-angled localised necking was observed at the laser cut edge after failure during HET due to the typical brittle nature of the recast 

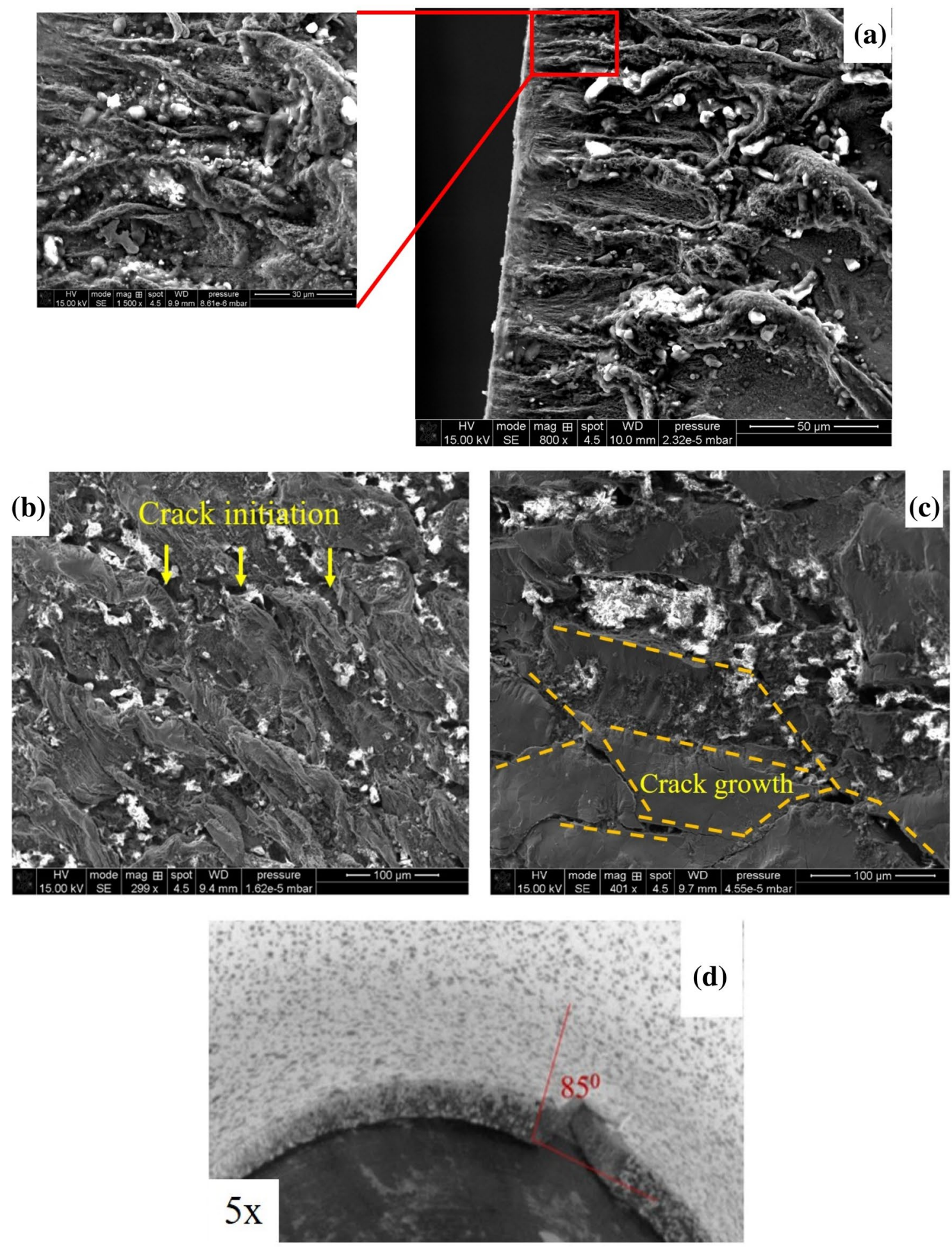

Fig. 12 SEM analysis of the crack mechanism after standard HET of laser cut edge: a laser cut surface, $\mathbf{b}$ failure initiation zone, $\mathbf{c}$ inter-granular crack growth (yellow dash lines), $\mathbf{d}$ brittle crack edge

region and hence the poor edge formability, as shown in Fig. 12 d.

Figure 13 shows the SEM micrographs for the AWJ cut edge before and after HET. The micrograph of the AWJ machined edge shows surface defects in the form of micro-grooves produced by the path traversed by abrasive particles as well as micro-voids occupied and vacated by abrasive particles, as shown in Fig. 13a. During HET, the

\section{SN Applied Sciences}



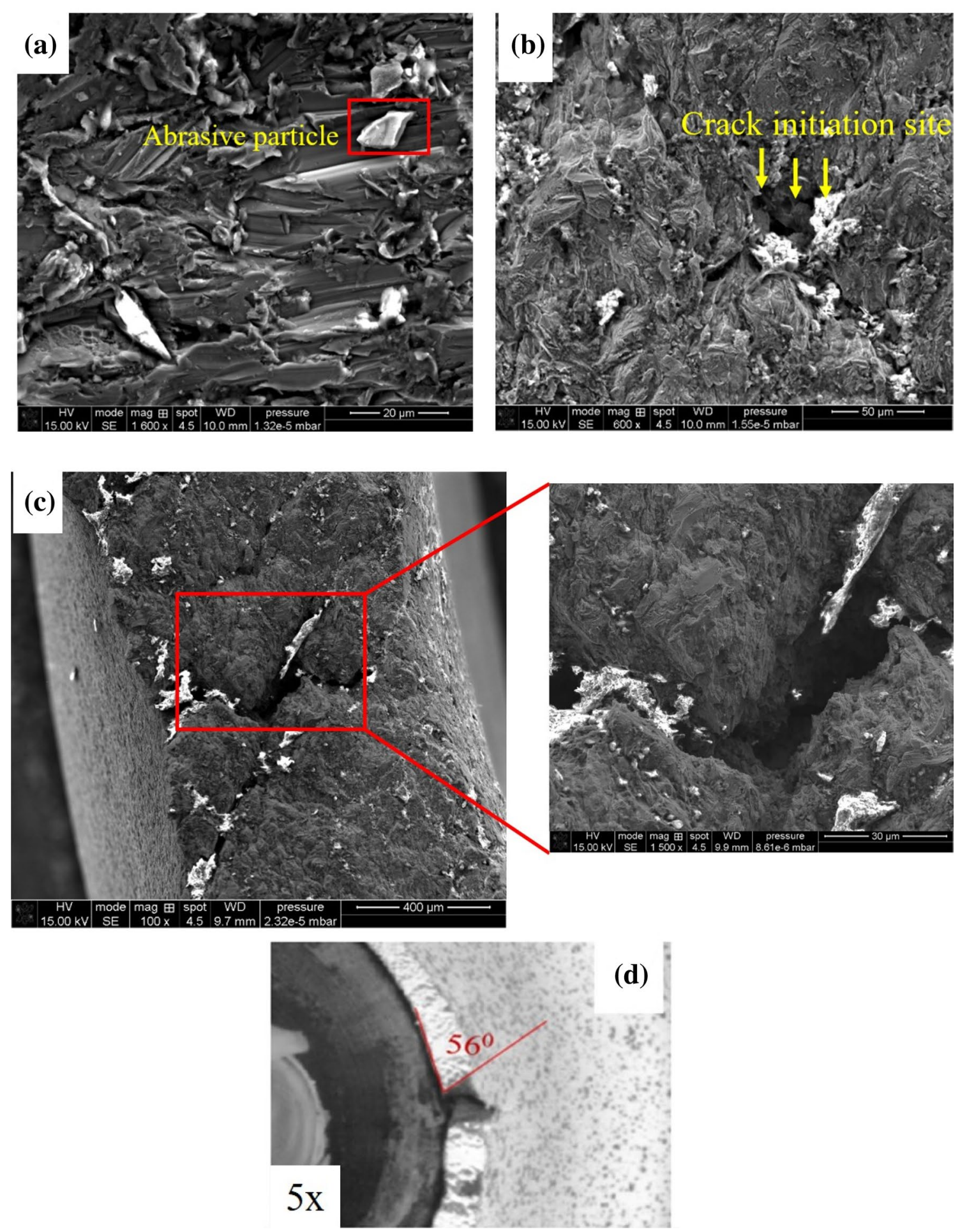

Fig. 13 SEM analysis of the mechanism of failure with AWJ cut surface: a cut AWJ surface, $\mathbf{b}$ crack initiation site after HET, $\mathbf{c}$ crack growth, $\mathbf{d}$ AWJ crack edge

micro-voids act as concentrated stress raisers, thereby acting as crack initiation sites, as shown in Fig. 13b. A general reduction in the edge thickness at zones where the crack propagated and grew was also observed, as shown in Fig. 13c. This could also be attributed to the more random distribution of the surface dragline features, which obstructed a quick crack growth. The cracks edge after HET also exhibited localised necking representative of a more 
ductile fracture since no heat-affected zones are associated with the AWJ cutting method, as shown in Fig. 13d.

Figure 14 also shows the SEM micrograph of the examined EDM cut test sample. The micrograph of the EDM cut surface is characterised by surface defects in the form of craters, micro-voids as well as re-solidified molten materials left behind during the machining process, as shown in Fig. 14a. Strain gradients produced during the machining process by thermal stresses during cooling and/or plastic deformation would appear to have created an environment for fine surface cracks to be produced on the workpiece edge surface, as shown in Fig. 14b. These
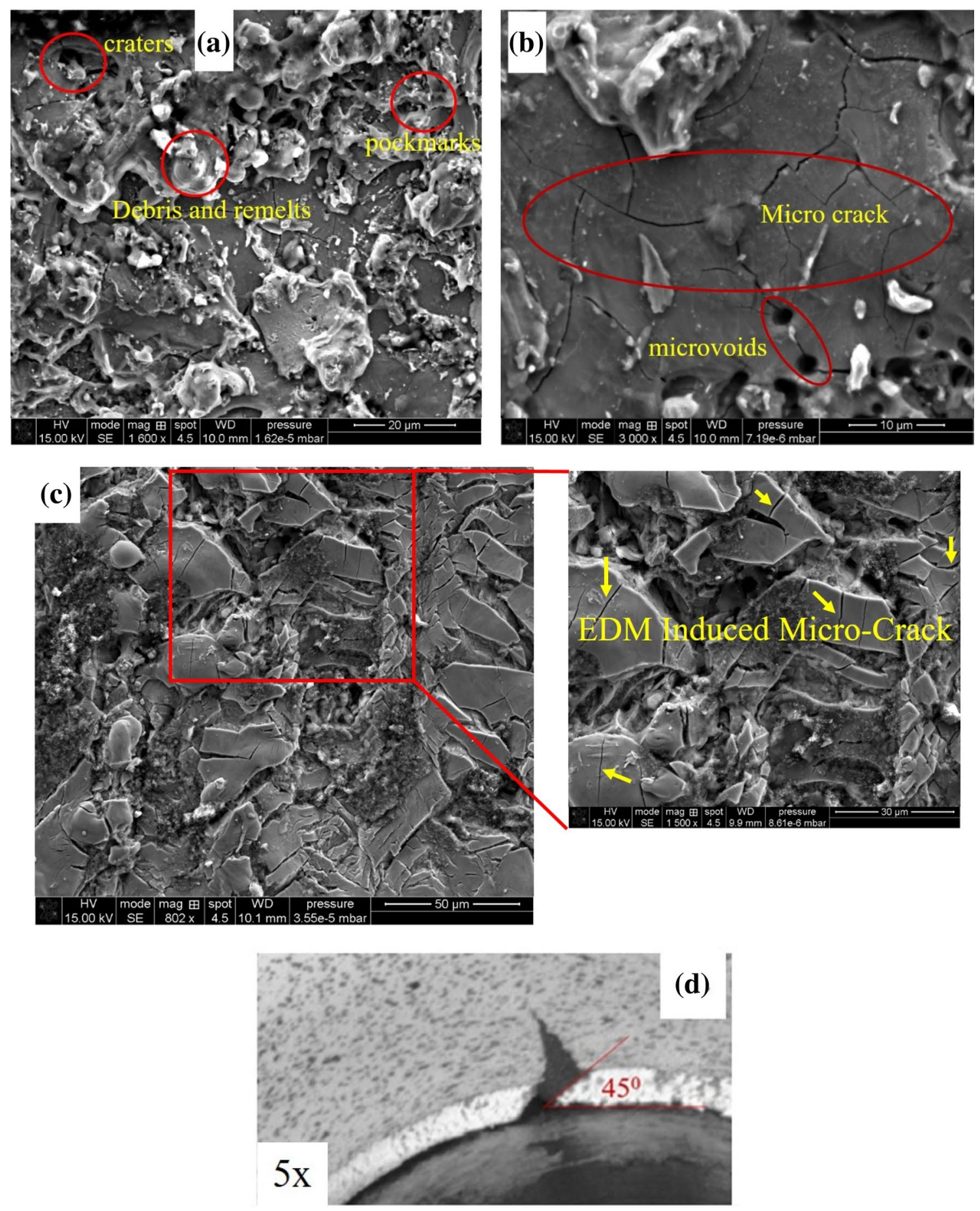

Fig. 14 SEM analysis of the mechanism of failure with EDM cut surface: (a), b cut EDM cut surface, $\mathbf{c}$ fractured EDM surface after HET with no significant growth in initial EDM-induced micro-crack width (yellow arrows), d EDM crack edge 
surface cracks spread the applied stress during HET uniformly around the hole edge and resist crack propagation towards the sheet thickness direction, thereby delaying premature fracture. The integrity of the EDM-induced micro-crack width (yellow arrows) was largely maintained after the HET, as shown in Fig. 14c.

Similar roles of strain-induced surface cracks generated after punching of single-phase steels inhibiting crack growth in the depth direction and consequently enhancing the material's HER have been reported by Hasegawa et al. [21]. These attributes of EDM cut edges are responsible for their superior edge formability compared to the other manufacturing methods. Inspection of the failed edge after HET also revealed that the EDM cut edge samples exhibited localised necking coupled with ductile shear fracture, as shown in Fig. 14d. This could be attributed to the exerted shear stresses at the hole edge during HET being transformed to uniaxial stress state during the necking period. The acting shear stresses are optimum when acting at $45^{\circ}$ to the applied load, thereby producing failure at zones where the shear stresses are highest. $[20,21]$

\section{Conclusions}

This research focused on the influence of machininginduced defects on the edge performance of CP-Ti (grade 2) after laser, EDM and AWJ cutting. The hole expansion test was conducted using a standard conical punch with a $60^{\circ}$ head and a hemispherical punch. The work also introduced the GOM ATOS non-contact metrology technique as a supplementary method of characterising the edge formability of materials. The work found that

- The variability of edge surface finish attained after EDM and AWJ machining can have a significant effect on the edge formability of CP-Ti (grade 2) sheet at room temperature.

- The EDM-machined edges showed higher edge formability tendencies compared to AWJ and laser cut edges. The material also showed a higher edge fracture limit strain for EDM cut edges ( 0.93) compared to the other machining methods (laser 0.34 and AWJ 0.53).

- Both hemispherical and conical punch tool geometries produced the same trend of sheet edge formability. The standard conical punch, however, produced a higher HER due to the tool loading orientation.

- GOM ATOS metrology offers a viable supplementary approach to characterising the edge formability of materials. The thinning evolution trends observed after GOM ATOS metrology are consistent with the trends observed after HET.
- Machining-induced surface defects serve as stress raisers during HET. The machining-induced microstructural changes also play a major role in governing the crack propagation and growth during the edge degradation process.

- The laser cut edges after HET are characterised by brittle inter-granular cracks. The surface cracks are brittle in nature and rapidly propagate across the laser cut edge due to the brittle nature of their surface recast layer, resulting in their reduced formability. The AWJ edge surface after HET was characterised by random distribution of surface dragline attributes, which hindered quick crack growth. The edge cracks after HET also exhibited localised necking representative of a more ductile fracture. The EDM cut edge after HET attained the highest HER due to the action of the strain gradients produced at the hole edge as a consequence of machining-induced plastic deformation resulting in surface cracks. These surface cracks resist crack growth in the sheet thickness direction, hence delaying failure during HET.

Acknowledgements The authors acknowledge the support of the Advance Forming Research Centre (AFRC) and the Department of Design, Manufacturing and Engineering Management of the University of Strathclyde. The authors also acknowledge the support of TIMET for the material donation.

\section{Compliance with ethical standards}

Conflict of interest On behalf of all authors, the corresponding author states that there is no conflict of interest.

Open Access This article is licensed under a Creative Commons Attribution 4.0 International License, which permits use, sharing, adaptation, distribution and reproduction in any medium or format, as long as you give appropriate credit to the original author(s) and the source, provide a link to the Creative Commons licence, and indicate if changes were made. The images or other third party material in this article are included in the article's Creative Commons licence, unless indicated otherwise in a credit line to the material. If material is not included in the article's Creative Commons licence and your intended use is not permitted by statutory regulation or exceeds the permitted use, you will need to obtain permission directly from the copyright holder. To view a copy of this licence, visit http://creativecommons .org/licenses/by/4.0/.

\section{References}

1. Pervaiz S, Rashid A, Deiab I, Nicolescu M (2014) Influence of tool materials on machinability of titanium and nickel based alloys: a review. Mater Manuf Process 29(3):219-252. https://doi. org/10.1080/10426914.2014.880460

2. Nasiri-Abarbekoh H, Ekrami A, Ziaei-Moayyed AA, Shohani M (2012) Effects of rolling reduction on mechanical properties 
anisotropy of commercially pure titanium. Mater Des 34:268274. https://doi.org/10.1016/j.matdes.2011.06.024

3. Jurendić S, Gaiani S (2013) Numerical simulation of cold forming of a-titanium alloy sheets. Strojniški vestnik J Mech Eng 59(3):148-155. https://doi.org/10.5545/sv-jme.2012.415

4. Kim BJ, Choi KH, Park KS, van Tyne CJ, Moon YH (2007) Effect of the surface defects on hydroformability of aluminum alloys. Key Eng Mater 340-341:587-592. https://doi.org/10.4028/www. scientific.net/KEM.340-341.587

5. Yamaguchi K, Takakura N, Imatani S (1995) Increase in forming limit of sheet metals by removal of surface roughening with plastic strain (Balanced biaxial stretching of aluminium sheets and foils). J Mater Process Technol 48(1-4):27-34. https://doi. org/10.1016/0924-0136(94)01629-F

6. Colafemina JP, Jasinevicius RG, Duduch JG (2007) Surface integrity of ultra-precision diamond turned $\mathrm{Ti}$ (commercially pure) and Ti alloy (Ti-6Al-4V). Proc IMechE Part B J Eng Manuf 221:9991006. https://doi.org/10.1243/09544054JEM798

7. Veiga C, Davim JP, Loureiro AJR (2013) Review on machinability of titanium alloys: the process perspective. e-J Rev Adv Mater Sci 34(2):148-164

8. Donachie MJ (1988) Titanium: a technical guide. ASM International, Ohio

9. Chuahan SR, Dass K (2012) Optimisation of machining parameters in turning of titanium (Grade 5 ) alloy using response surface methodology. Mater Manuf Process 27(5):531-537. https://doi. org/10.1080/10426914.2011.593236

10. Che-Haron $\mathrm{CH}$, Jawaid A (2005) The effect of machining on surface integrity of titanium alloy Ti-6Al-4V. J Mater Process Technol 166(2):188-192. https://doi.org/10.1016/j.jmatprotec 2004.08.012

11. Hascalik A, Caydas U (2007) Electrical discharge machining of titanium alloy (Ti-6Al-4V). Appl Surf Sci 253(22):9007-9016. https://doi.org/10.1016/j.apsusc.2007.05.031

12. Hascalik A, Caydas U, Gurun H (2007) Effect of traverse speed on abrasive waterjet machining of Ti-6Al-4V alloy. Mater Des 28:1953-1957. https://doi.org/10.1016/j.matdes.2006.04.020

13. Mori Kl, Abe Y, Suzui Y (2010) Improvement of stretch flangeability of ultra high strength steel sheet by smoothing of sheared edge. J Mater Process Technol 210(4):653-659. https://doi. org/10.1016/j.jmatprotec.2009.11.014
14. Silva MB, Teixeira P, Reis A, Martins PAF (2013) On the formability of hole-flanging by incremental sheet forming. Proc Inst Mech Eng Part L J Mater Des Appl 227:91-99. https://doi. org/10.1177/1464420712474210

15. Atzema E, Bortsutzki M, Braun M, Brockmann S, Bulter M, Carlsson B, Larour P, Richter A (2012) A European round robin test for the hole expansion test according to ISO 16630. In Proceeding of International Conference: New Development in Sheet Metal Forming, Fellbach, Germany

16. Larour P, Freudenthaler J, Grünsteidl A, Wang K (2014) Evaluation of alternative stretch flageability testing methods to ISO 16630 standard. Innovations for the sheet metal industry. In Proceedings of the IDDRG Conference, Paris, France

17. Nasiri-Abarbekoh H, Ekrami A, Ziaei-Moayyed AA (2013) Effects of thickness and texture on mechanical properties anisotropy of commercially pure titanium thin sheets. Mater Des 44:528-534. https://doi.org/10.1016/j.matdes.2012.08.046

18. Yi N, Hama T, Kobuki A, Fajumoto H, Takuda H (2016) Anisotropic deformation behavior under various strain paths in commercially pure titanium Grade 1 and Grade 2 sheet. Mater Sci Eng A 655:70-85. https://doi.org/10.1016/j.msea.2015.12.081

19. Gläsner T, Schneider $M$, Troitzsch $M$, Westhäuser $S$ (2016) Considering the edge-crack sensitivity of a hot-rolled steel in forming simulation. IOP Conf Ser Mater Sci Eng 159:1-17. https://doi. org/10.1088/1757-899X/159/1/012029

20. Pathak N, Butcher C, Worswick M (2016) Assessment of the critical parameters influencing the the edge stretchability of advanced high-strength steel sheet. J Mater Eng Perform 25:4919-4932. https://doi.org/10.1007/s11665-016-2316-9

21. Hasegawa K, Kawamura K, Urabe T, Hosoya Y (2004) Effects of microstructure on stretch- flange- formability of $980 \mathrm{MPa}$ grade cold- rolled ultra-high strength steel sheets. ISIJ Int 44(3):603609. https://doi.org/10.2355/isijinternational.44.603

Publisher's Note Springer Nature remains neutral with regard to jurisdictional claims in published maps and institutional affiliations. 